\title{
Metal-metal multiple bonded intermediates in catalysis
}

\author{
JOHN F BERRY \\ Department of Chemistry, University of Wisconsin - Madison, 1101 University Ave., Madison, \\ WI 53706, USA \\ e-mail: berry@chem.wisc.edu
}

MS received 19 May 2014; accepted 17 July 2014

\begin{abstract}
Metal-metal bonded $\mathrm{Rh}_{2}$ and $\mathrm{Ru}_{2}$ complexes having a paddlewheel-type structure are exceptional catalysts for a broad range of organic transformations. I review here the recent efforts towards the observation and characterization of intermediates in these reactions that have previously eluded detection. Specifically, mechanistic investigations of carbenoid and nitrenoid reactions of $\mathrm{Rh}_{2}$ (II,II)-tetracarboxylate compounds have led to the observation of a metastable $\mathrm{Rh}_{2}$ (II,II) carbene complex as well as a mixed-valent $\mathrm{Rh}_{2}$ (II,III)-amido intermediate. Related $\mathrm{Ru}_{2}$ nitrido compounds have been studied and found to undergo intramolecular $\mathrm{C}-\mathrm{H}$ amination reactions as well as intermolecular reaction with triphenylphosphine.
\end{abstract}

Keywords. Catalysis; metal-metal bonds; carbene; nitrene; nitride.

\section{Introduction}

Since the recognition of the first metal-metal quadruple bond 50 years ago, ${ }^{1}$ metal-metal bonded paddlewheeltype complexes have been extensively studied with respect to their structural, spectral, redox and chemical properties. $^{2}$ One of the foremost applications of these compounds is in the area of catalysis, where dirhodium tetracarboxylate compounds in particular, have been shown to catalyse a wide number of carbene- and nitrene-transfer reactions. The most spectacular of these catalytic reactions involve the insertion of a carbene or nitrene into unactivated $\mathrm{C}-\mathrm{H}$ bonds (scheme 1 ). ${ }^{3-9}$ These catalytic reactions are presumed to occur via the intermediacy of discrete $\mathrm{Rh}_{2}$-carbene or $\mathrm{Rh}_{2}$-nitrene complexes that feature a proposed linear $\mathrm{Rh}-\mathrm{Rh}=\mathrm{E}$ unit, where $\mathrm{E}=$ the carbene or nitrene fragment. Studies aimed at elucidating the mechanism of these reactions with special emphasis on the detection and spectroscopic characterization of the proposed $\mathrm{Rh}-\mathrm{Rh}=\mathrm{E}$ species, are reviewed here. The efforts to characterize related $\mathrm{Ru}-\mathrm{Ru} \equiv \mathrm{N}$ nitrido compounds are also discussed.

\section{2. $\mathbf{R h}_{2}$ carbene chemistry}

Early studies of $\mathrm{Rh}_{2}$-catalysed carbenoid reactions led to the postulation of a discrete $\mathrm{Rh}_{2}$-carbene complex as an intermediate in the reaction, primarily on the basis of reaction selectivity. ${ }^{10-12}$ An illuminating study reported in 1984 by Doyle and co-workers showed a strong correlation between reaction products of $\mathrm{Rh}_{2}$-catalysed reactions and those obtained from stoichiometric reactions of an isolated $\mathrm{W}$-carbene complex, ${ }^{13}$ thus strongly implicating an $\mathrm{Rh}_{2}$ carbene complex as an intermediate. Computational studies have also been highly informative and suggest a linear $\mathrm{Rh}-\mathrm{Rh}=\mathrm{CR}_{2}$ geometry for the postulated carbene intermediate. ${ }^{14-18}$ The calculated electronic structure of this intermediate has been extensively described by Nakamura and co-workers ${ }^{16}$ and was further refined by Berry. ${ }^{19}$ The key electronic feature of this intermediate is delocalized $\mathrm{Rh}-\mathrm{Rh}-\mathrm{C}$ three-centre bonding with appropriate three-centre orbitals of $\sigma$ and $\pi$ symmetry. The resulting $\mathrm{Rh}-\mathrm{Rh}-\mathrm{C}$ three-centre/four-electron bonds of $\sigma$ and $\pi$ symmetry lead to a description of the $\mathrm{Rh}=\mathrm{C}$ bond as being weak with only partial $\sigma$ character and partial $\pi$ character, and the $\mathrm{Rh}=\mathrm{C}$ bond is calculated to have an overall bond order of $\sim 0.7-$ 0.8 . Notably, the LUMO of the carbene complex has a significant degree of empty $\mathrm{p}$ orbital character on the $\mathrm{C}$ atom, providing a strong rationale for its highly electrophilic reactivity.

An important issue that has been investigated both experimentally and computationally is the nature and effect of the substituents on the carbene $\mathrm{C}$ centre. Organic diazo compounds are almost exclusively used as carbene precursors in $\mathrm{Rh}_{2}$-catalysed reactions, and three general classes of these compounds have been studied (scheme 2). ${ }^{4,20}$ Diazo compounds bearing two electron accepting groups (A/A compounds, in which the A groups are typically esters) are quite stable and may require forcing conditions to react with the $\mathrm{Rh}_{2}$ catalyst. The carbenes derived from A/A diazo compounds 


\section{Carbenoid C-H functionalization}

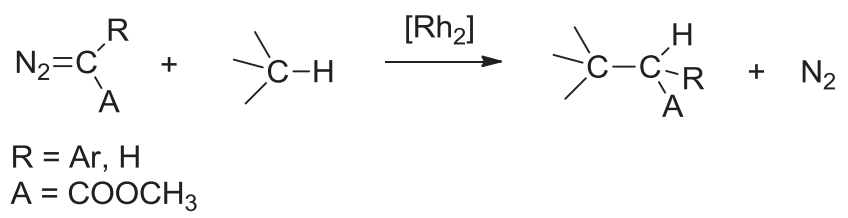

\section{Nitrenoid $\mathrm{C}-\mathrm{H}$ amination}

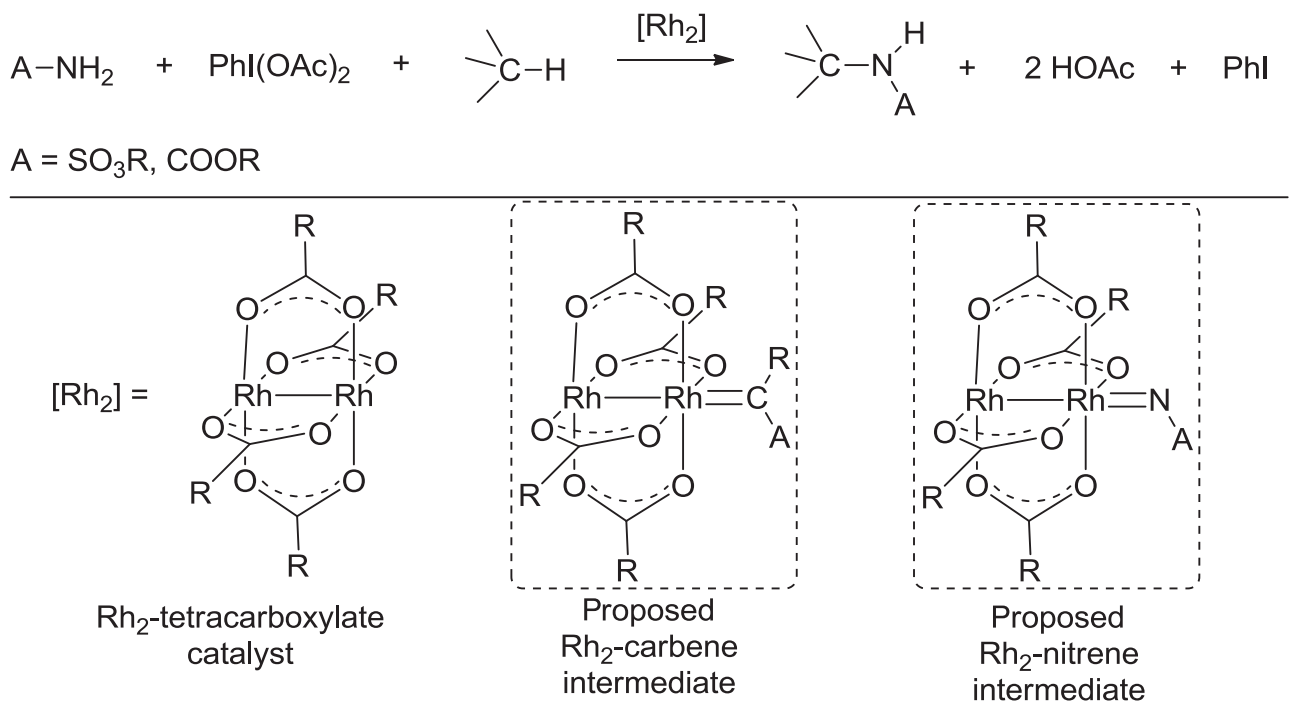

Scheme 1. Overview of $\mathrm{Rh}_{2}$-catalysed $\mathrm{C}-\mathrm{H}$ functionalization chemistry.

are highly reactive and react indiscriminately with $\mathrm{C}-\mathrm{H}$ bonds, even in the presence of $\mathrm{Rh}_{2}$ catalysts. The most widely used diazo compounds are those with only one acceptor group (A-only; e.g., the commercially available ethyl diazoacetate). For these species, loss of $\mathrm{N}_{2}$ is still the most important, and rate-limiting, reaction step. Diazo compounds that bear both an electron acceptor group and an electron donor group (D/A compounds) have a number of appealing properties. Loss of $\mathrm{N}_{2}$ from these species is more readily achieved. Also, the carbene formed from these species is stabilized by the presence of the electron donor group and is therefore not as reactive as the A-only or A/A species. Thus, $\mathrm{C}-\mathrm{H}$ functionalization from a D/A carbene is, in general, more selective than with other carbene precursors.

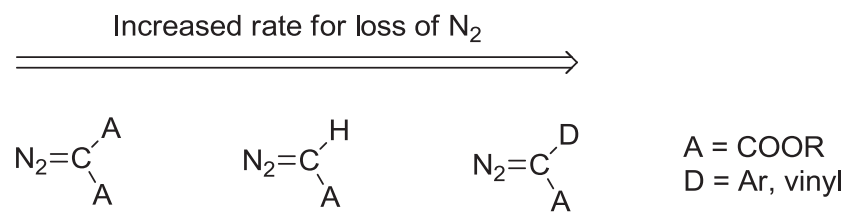

Increased selectivity for $\mathrm{C}-\mathrm{H}$ functionalization

Scheme 2. Trends in reactivity for the different classes of organic diazo compounds.
Using such D/A precursors, elegant means of controlling the regio- and stereoselectivity of these reactions have been developed. ${ }^{4,6,20}$

The reaction coordinate for the loss of $\mathrm{N}_{2}$ and functionalization of cyclopentane has been evaluated computationally for ethyl diazoacetate (A-only) as well as ethyl phenyldiazoacetate (D/A). ${ }^{18}$ The major calculated difference in these reactions is that the carbene intermediate was found to be significantly more stable for D/A substrate than for the A-only substrate, in the order of $\sim 40 \mathrm{~kJ} / \mathrm{mol}^{18}{ }^{18}$ This result suggested that a $\mathrm{Rh}_{2}$ D/A carbene complex might be stable enough to be observed.

Indeed, the combination of the very bulky $\mathrm{Rh}_{2}$ tetrakis(triphenylcarboxylate) $\left(\mathrm{Rh}_{2}(\mathrm{TPA})_{4}\right)$ complex with the D/A diazo compound methyl 4-methoxyphenyldiazoacetate led to the observation of a deep blue metastable species that is stable for $\sim 20 \mathrm{~h}$ at $0^{\circ} \mathrm{C}$ in chlorinated (and deuterated) solvents (scheme 3). ${ }^{21}$ The identity of this intermediate as the first observed metastable $\mathrm{Rh}_{2}$ carbene complex was confirmed by a suite of spectroscopic methods. ${ }^{13} \mathrm{C}$ NMR spectroscopy and resonance Raman spectroscopy were used to establish the $\mathrm{Rh}=\mathrm{C}$ linkage, while EXAFS analysis allowed for a determination of the $\mathrm{Rh}-\mathrm{Rh}$ bond length of $2.43 \AA .^{21}$ Results from DFT calculations were in agreement with all 


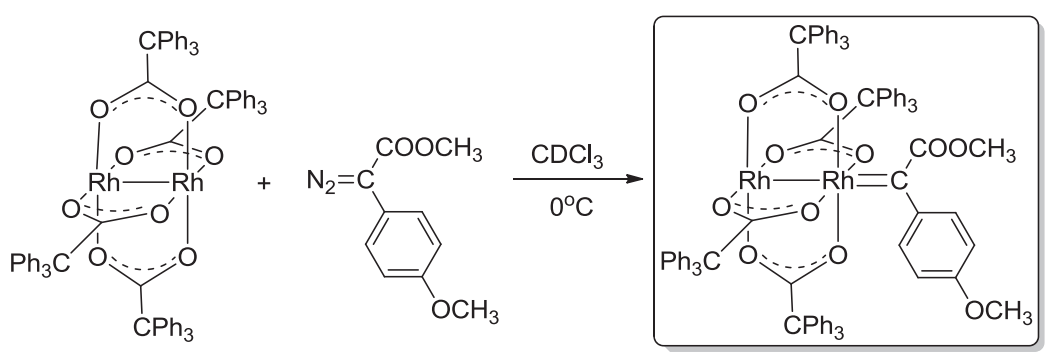

Scheme 3. Preparation of the first $\mathrm{Rh}_{2} \mathrm{D} / \mathrm{A}$ carbene complex.

the spectroscopic observables, and the reactivity of the intermediate was found to be consistent with catalytic reactions involving $\mathrm{Rh}_{2}(\mathrm{TPA})_{4}$. Specifically, cyclopropanation of styrene and insertion into the $\mathrm{C}-\mathrm{H}$ bond of tetrahydrofuran were observed. ${ }^{21}$

\section{3. $\mathbf{R h}_{2}$ nitrene chemistry}

$\mathrm{Rh}_{2}$-catalysed nitrenoid chemistry is mechanistically more complex than the corresponding carbenoid chemistry. This is mainly because an external oxidant, typically a hypervalent organoiodine reagent, is utilized to generate the nitrene species in situ. ${ }^{8}$ Mechanistic studies by the Du Bois lab have uncovered a number of critical observations. First, kinetic analysis indicated that the rate-limiting step is a likely reaction of the nitrogen substrate with the oxidant to form an iminoiodinane species, ${ }^{22,23}$ which is envisioned to react in a subsequent step with the $\mathrm{Rh}_{2}$ catalyst to form an $\mathrm{Rh}_{2}$ nitrene complex. Several proposed intermediates for these reactions have been implicated as being catalytically relevant on the basis of signals observed in mass spectra taken in situ. ${ }^{24}$ A growing amount of experimental evidence suggests that these reactions are even more complex than what would be expected from a simple nitrene interception/insertion mechanism. For example, there are distinct mechanistic differences for $\mathrm{C}-\mathrm{H}$ amination depending on whether the reaction is intramolecular or intermolecular. The data in scheme 4 provide a poignant example. These reactions on isolated iminoiodinane compounds were performed as a test of the competence of the proposed iminoiodinane intermediates. ${ }^{22,23}$ For the intramolecular cyclization in scheme $4 \mathrm{a}$, the yield of the product is comparable to that of a catalytic reaction in which the iminoiodinane is formed in situ. However, an analogous intermolecular reaction, scheme $4 \mathrm{~b}$, produces the $\mathrm{C}-\mathrm{H}$ amination product in significantly lower yield $(33 \%)$ than under in situ conditions $(\sim 70 \%)$, suggesting that there may be an alternative catalytic mechanism that bypasses iminoiodinane intermediates. Another intriguing difference between intra- and intermolecular reactions is that the reaction mixture turns a persistent red colour in the latter case but only sometimes in the former. ${ }^{23,25}$ This red colour has been attributed to a one-electron oxidized form of the catalyst, either $\left[\mathrm{Rh}_{2}(\mathrm{esp})_{2}\right]^{+}$or $\mathrm{Rh}_{2}(\mathrm{esp})_{2} \mathrm{Cl}$, from which it was hypothesized that catalyst degradation occurs readily (here, esp $=\alpha, \alpha, \alpha^{\prime}, \alpha^{\prime}$-tetramethyl1,3-benzenedipropanoate). ${ }^{23,25}$

My lab recently reported further, direct evidence of multiple mechanistic pathways for intermolecular $\mathrm{C}-\mathrm{H}$ amination. For the intermolecular $\mathrm{C}-\mathrm{H}$ amination reaction of ethylbenzene with $\mathrm{H}_{2}$ NTces (Tces = trichloroethylsulphonate) in the presence of $\mathrm{PhI}(\mathrm{OAc})_{2}$, a plot of product concentration vs. time shows that product formation occurs quickly in an initial burst of reactivity in the first 5-10 min, but continues after this initial burst to produce a significant amount of further product at a slower rate. ${ }^{26}$ In efforts to explain this unusual reactivity as well as to elucidate the role of putative one-electron oxidized $\mathrm{Rh}_{2}$ (II,III) species that had been observed during the course of the reaction, bulk coulometric oxidation of the $\mathrm{Rh}_{2}(\mathrm{esp})_{2}$ catalyst

(a)
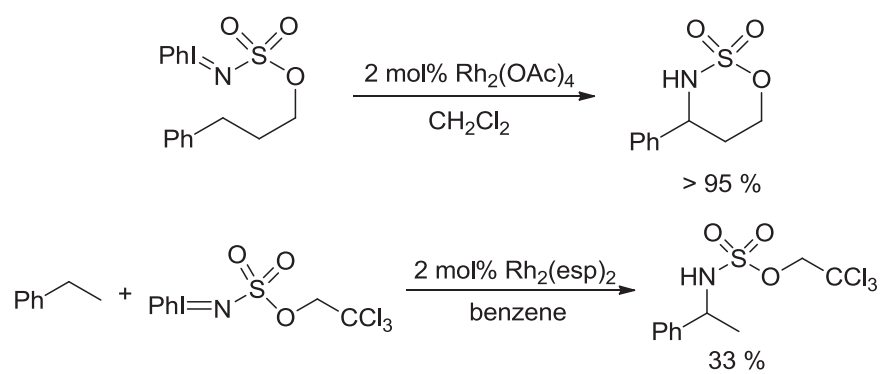

a)

(b)

$33 \%$

Scheme 4. Reactions using pre-formed iminoiodinane compounds. 
was explored. This experiment led to the identification of a one-electron oxidized $\mathrm{Rh}_{2}$ (II,III)-amido species, $\mathrm{Rh}_{2}$ (esp) ${ }_{2}$ (HNTces) (A in scheme 5), which matched the spectroscopic features observed during catalysis. ${ }^{26}$ A was found to be competent for $\mathrm{C}-\mathrm{H}$ amination since it reacts with $\mathrm{PhI}(\mathrm{OAc})_{2}$ in the presence of substrate to regenerate the $\mathrm{Rh}_{2}(\mathrm{esp})_{2}$ catalyst in its unoxidized form. From these data, the double catalytic cycle for $\mathrm{C}-$ $\mathrm{H}$ amination shown in scheme 5 was proposed. ${ }^{26}$ The inner reaction cycle is essentially the same as that proposed by Du Bois involving group transfer from iminoiodinane species, whereas the outer cycle relies on proton-coupled electron transfer steps to avoid the formation of an iminoiodinane species. The inner cycle is likely responsible for the fast initial burst of reactivity, and the outer reaction cycle appears to be the slower reaction that dominates product formation at longer reaction times. ${ }^{26}$

Interestingly, when the esp ligand is exchanged for structurally analogous ligands that are redox noninnocent, only ligand-centreed oxidation chemistry is observed. ${ }^{27}$ The $\mathrm{Rh}_{2}$ complexes bearing redox noninnocent ligands are only able to perform the initial burst of reactivity observed for $\mathrm{Rh}_{2}(\mathrm{esp})_{2}$ and then cease to function. Thus, these catalysts appear to only be capable of catalysis via the inner nitrene interception/insertion cycle of scheme 5 and cannot use the outer single-electron cycle of scheme $5 .{ }^{27}$ These results highlight the necessity for metal-centreed redox capability in intermolecular $\mathrm{C}-\mathrm{H}$ amination. In this case, ligand-centreed redox chemistry does not substitute for metal-centreed redox chemistry, and the electronic structure of the $\mathrm{Rh}_{2}$ (II,III) state appears to be suitable for carrying out $\mathrm{C}-\mathrm{H}$ amination. To test this idea,<smiles>CC(C)(Cc1cccc(CC(C)(C)C(=O)O)c1)C(=O)O</smiles><smiles>CC(C)(Cc1cccc(Cc2ccccc2)c1)C(N)=O</smiles>

Scheme 6. Structures of the esp and espn ligands.

the deliberate preparation of stable $\mathrm{Rh}_{2}$ (II,III) complexes has been pursued so that their performance in $\mathrm{C}-\mathrm{H}$ amination catalysis could be evaluated. As amply demonstrated by Doyle, ${ }^{28}$ it is possible to stabilize the $\mathrm{Rh}_{2}$ (II,III) oxidation state by using carboxamidate equatorial ligands rather than carboxlates. Thus, the redox chemistry of $\mathrm{Rh}_{2}(\mathrm{espn})_{2}$ was explored, in which the new ligand espn is the carboxamidate version of esp (scheme 6). ${ }^{29}$ The $\mathrm{Rh}_{2}$ (II,III) species $\mathrm{Rh}_{2}\left(\right.$ espn) ${ }_{2} \mathrm{Cl}$ is stable and was isolated as two isomers, both of which perform exceptionally well as catalysts for intramolecular $\mathrm{C}-\mathrm{H}$ amination. ${ }^{29}$ Owing to the expense and rarity of $\mathrm{Rh}$, lowering the catalyst loading required for $\mathrm{C}-\mathrm{H}$ amination is a major goal. With the $\mathrm{Rh}_{2}(\mathrm{espn})_{2} \mathrm{Cl}$ catalyst, a maximum turnover number of 1400 at a catalyst loading of $0.05 \mathrm{~mol} \%$ was achieved, ${ }^{29}$ which is, to our knowledge, the highest turnover number yet reported for $\mathrm{Rh}_{2}$-catalysed $\mathrm{C}-\mathrm{H}$ amination.

\section{4. $R \mathbf{u}_{2}$ Nitrido chemistry}

Noting that multiple-bonded $\mathrm{Rh}-\mathrm{Rh}=\mathrm{E}$ structures with $\mathrm{E}=\mathrm{CR}_{2}$ or $\mathrm{NR}$ are proposed as key intermediates in $\mathrm{Rh}_{2}$-catalysed carbenoid and nitrenoid reactions, respectively, it seemed likely that exploration of related

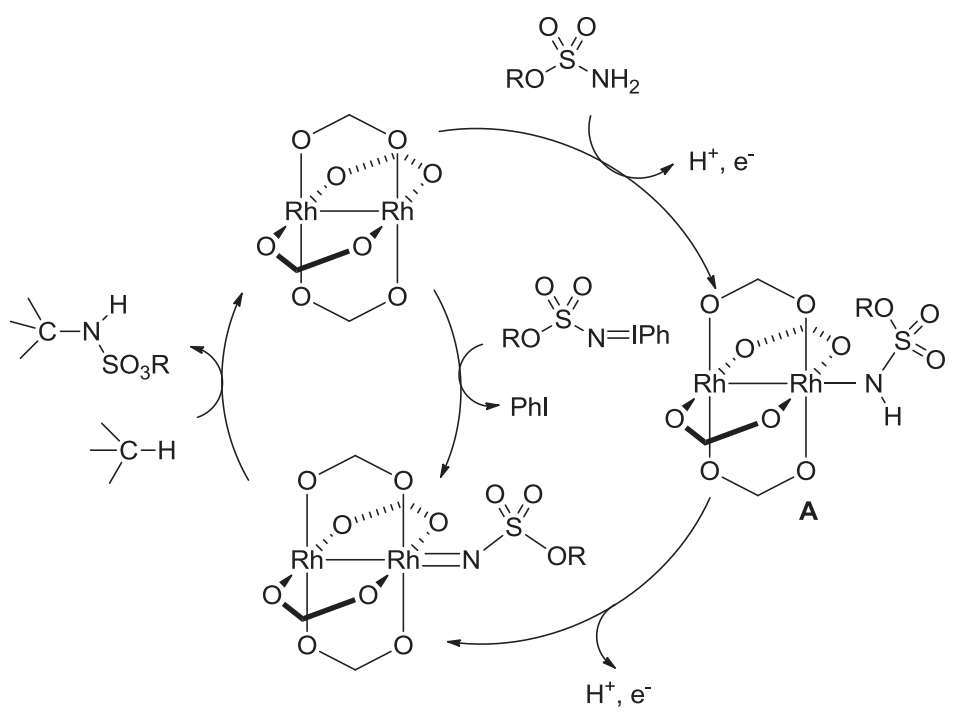

Scheme 5. Proposed mechanism for intermolecular C-H amination. Organic groups on the catalyst are removed for clarity. 


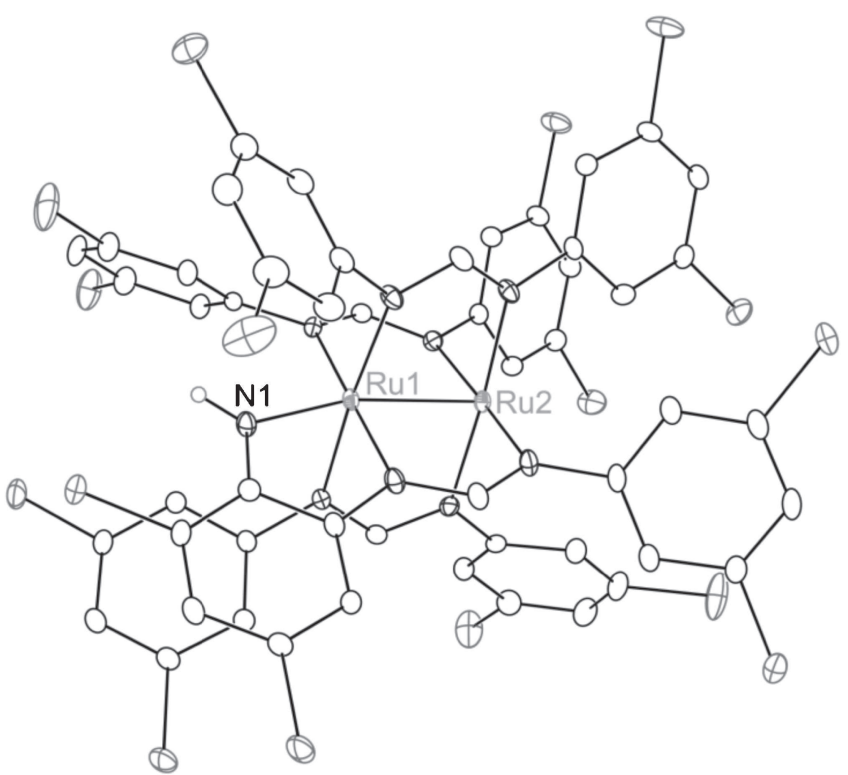

Figure 1. Crystal structure of $\mathrm{Ru}_{2}\left[\left(\mathrm{D}\left(3,5-\mathrm{Cl}_{2}\right) \mathrm{PhF}\right)_{3}(\mathrm{D}(3\right.$, $\left.\left.\left.5-\mathrm{Cl}_{2}-2-\mathrm{NH}\right) \mathrm{PhF}\right)\right]$.

$\mathrm{M}-\mathrm{M}=\mathrm{E}$ structures might be a fruitful avenue for the discovery of new reactivity. The first such complexes to be generated and characterized were $\mathrm{Ru}_{2}$ nitrido complexes having a linear $\mathrm{Ru}-\mathrm{Ru} \equiv \mathrm{N}$ structure. ${ }^{30}$

A number of $\mathrm{Ru}_{2}$ complexes bearing axial azide ligands were reported in $2005,{ }^{31}$ which, in principle, could serve as precursors for $\mathrm{Ru}_{2}$-nitrido compounds. The first $\mathrm{Ru}_{2}$ nitrido compound, $\mathrm{Ru}_{2}(\mathrm{DPhF})_{4} \mathrm{~N}$ $\left(\mathrm{DPhF}=\mathrm{N}, \mathrm{N}^{\prime}\right.$-diphenylformamidinate), originally prepared by cryogenic photolysis of the corresponding azido complex, ${ }^{30}$ was found to be thermally unstable. In an effort to understand the nature of this instability, the related $\mathrm{Ru}_{2}\left(\mathrm{D}\left(3,5-\mathrm{Cl}_{2}\right) \mathrm{PhF}\right)_{4} \mathrm{~N}_{3}$ azide complex was investigated, in which the supporting ligands have chloro substituents at the 3,5 positions of all the aryl rings. Using this azide complex, it was possible to expel
$\mathrm{N}_{2}$ cleanly via thermolysis rather than photolysis. ${ }^{32}$ The stable product obtained after thermolysis was not the nitrido complex; it was instead the compound shown in figure 1 in which the $\mathrm{N}$ atom of a putative $\mathrm{Ru}_{2}$ nitride inserted into an aryl $\mathrm{C}-\mathrm{H}$ bond of one of the $\mathrm{D}(3,5-$ $\left.\mathrm{Cl}_{2}\right) \mathrm{PhF}$ ligands. ${ }^{32}$ A nitride intermediate was implicated in this study by the fact that differential scanning calorimetry (DSC) of the $\mathrm{Ru}_{2}$-azide precursor showed two distinct features, each associated with an exothermic chemical transformation. This result is consistent with a mechanism involving two steps: exothermic loss of $\mathrm{N}_{2}$ from the azide group to form a nitrido intermediate, followed by exothermic insertion of the nitride into the ligand $\mathrm{C}-\mathrm{H}$ bond. ${ }^{32}$ In further support of this general mechanism, an analogous $\mathrm{C}-\mathrm{H}$ insertion product was obtained upon thawing out a frozen solution of the original $\mathrm{Ru}_{2}(\mathrm{DPhF})_{4} \mathrm{~N}$ nitrido complex. ${ }^{32}$

Computational results on the $\mathrm{Ru}_{2}$ nitrido system indicated that the $\mathrm{C}-\mathrm{H}$ amination reaction follows an electrophilic aromatic substitution mechanism in which the nitride $\mathrm{N}$ atom is the electrophile. ${ }^{33}$ The nitrido $\mathrm{N}$ atom is rendered electrophilic via the same three-centre/fourelectron bonding manifold that is operative in the $\mathrm{Rh}_{2}$ carbene and $\mathrm{Rh}_{2}$-nitrene intermediates. ${ }^{19}$ Further computational study has explored the energetics of the electrophilic aromatic substitution mechanism using a series of hypothetical $\mathrm{M}-\mathrm{Ru} \equiv \mathrm{N}$ and $\mathrm{M}-\mathrm{Mo} \equiv \mathrm{N}$ compounds as well as mononuclear $\mathrm{Ru} \equiv \mathrm{N}$ and $\mathrm{Mo} \equiv \mathrm{N}$ models, in order to determine the role of the metalmetal bond in $\mathrm{C}-\mathrm{H}$ amination reactivity. ${ }^{34}$ Through analysis of all the energetics of these reactions, two generalizations were made. First, transition state energies were uniformly higher in energy for mononuclear $\mathrm{M} \equiv \mathrm{N}$ compounds than they were for binuclear metalmetal bonded $\mathrm{M}_{2}$ nitrido compounds, signifying that the $\mathrm{M}-\mathrm{M} \equiv \mathrm{N}$ electronic structure greatly facilitates $\mathrm{C}-\mathrm{H}$ amination via the electrophilic aromatic substitution

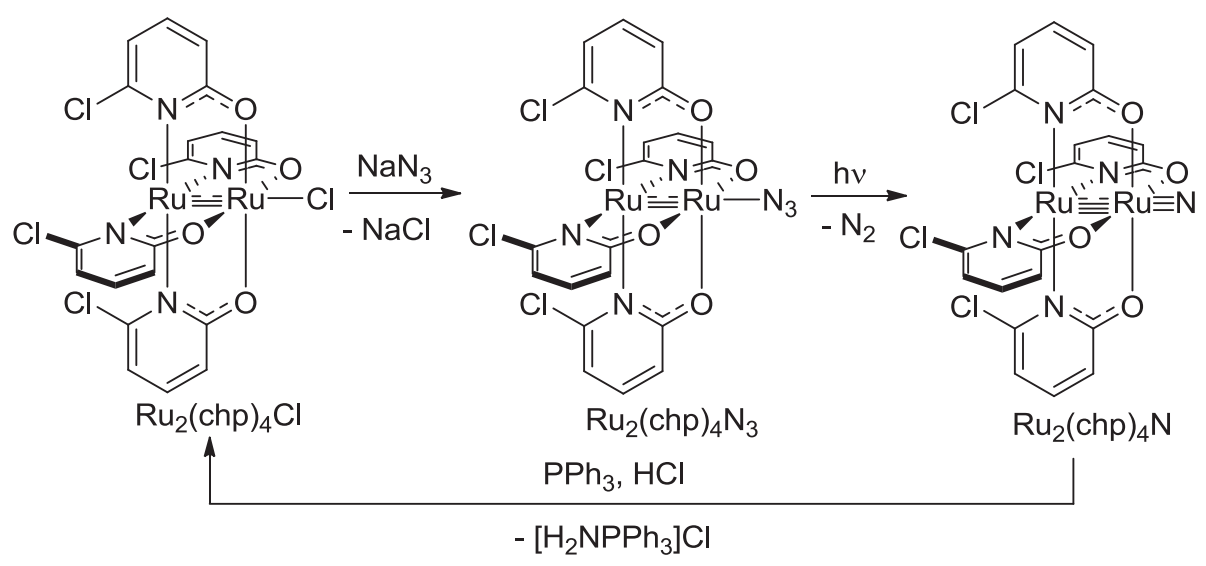

Scheme 7. Synthetic cycle for $\mathrm{N}$-atom transfer using the $\mathrm{Ru}_{2}(\operatorname{chp})_{4}$ core. 
pathway. Secondly, transition state energies were uniformly higher for $\mathrm{M}-\mathrm{Mo} \equiv \mathrm{N}$ compounds than they were for $\mathrm{M}-\mathrm{Ru} \equiv \mathrm{N}$ compounds, consistent with greater electrophilicity of the latter species. ${ }^{34}$

In order to disfavour intramolecular reactions, a new $\mathrm{Ru}_{2}$-nitride precursor was designed that utilizes the $\mathrm{Ru}_{2}(\mathrm{chp})_{4}$ core (chp = 6-chlorohydroxypyridinate). The compound $\mathrm{Ru}_{2}(\mathrm{chp})_{4} \mathrm{Cl}$ was reported in 1985 by Chakravarty et al. ${ }^{35}$ and its structure was found to have a '4.0' configuration in which all the $\mathrm{O}$ atoms bind to one $\mathrm{Ru}$ atom and all the $\mathrm{N}$ atoms bind to the other $\mathrm{Ru}$ atom as indicated in scheme 7. Replacement of the axial chloro ligand for azide produces $\mathrm{Ru}_{2}(\mathrm{chp})_{4} \mathrm{~N}_{3}$, which retains the '4.0' configuration and can therefore be used to produce a $\mathrm{Ru}_{2}$ nitrido species having no prospect for intramolecular reactivity. ${ }^{36} \mathrm{The} \mathrm{Ru}_{2}(\mathrm{chp})_{4} \mathrm{~N}$ nitrido complex, formed upon photolysis, is easily trapped by an intermolecular reaction with $\mathrm{PPh}_{3}$, from which the $\left[\mathrm{H}_{2} \mathrm{NPPh}_{3}\right]^{+}$ion can be obtained after acidic workup. ${ }^{36}$ Remarkably, the $\mathrm{Ru}_{2}(\mathrm{chp})_{4}$ core is resistant to the acidic conditions, and $\mathrm{Ru}_{2}(\mathrm{chp})_{4} \mathrm{Cl}$ can be regenerated to close a cycle for intermolecular $\mathrm{N}$ atom transfer. ${ }^{36}$

\section{Summary}

Efforts to identify reactive metal-metal bonded complexes having a linear $\mathrm{M}-\mathrm{M}=\mathrm{E}$ structure have led to the observation of important intermediates in $\mathrm{Rh}_{2}$-catalysed carbenoid and nitrenoid transformations. Inspired by the structures of these intermediates, we have been able to explore novel reactivity of the $\mathrm{Ru}-\mathrm{Ru} \equiv \mathrm{N}$ core including intramolecular $\mathrm{C}-\mathrm{H}$ amination as well as intermolecular $\mathrm{N}$ atom transfer.

\section{Acknowledgements}

I thank the US Department of Energy and the National Science Foundation for supporting my research under the following grants: DE-FG02-10ER16204, CHE1205646, and CHE-1300464.

\section{References}

1. Cotton F A, Curtis N F, Harris C B, Johnson B F G, Lippard S J, Mague J T, Robinson W R and Wood J S 1964 Science 1451305

2. Cotton F A, Murillo C A and Walton R A 2005 Multiple bonds between metal atoms (New York: Springer Science and Business Media, Inc.)

3. Doyle M P and Forbes D C 1998 Chem. Rev. 98911

4. Davies H M L and Beckwith R E J 2003 Chem. Rev. 103 2861

5. Davies H M L and Manning J R 2008 Nature 451417
6. Doyle M P, Duffy R, Ratnikov M and Zhou L 2010 Chem. Rev. 110704

7. Du Bois J 2011 Org. Proc. Res. Dev. 15758

8. Roizen J L, Harvey M E and Du Bois J 2012 Acc. Chem. Res. 45911

9. Kornecki K P, Powers D C, Ritter T and Berry J F 2014 In Prog. Inorg. Chem., Karlin K D (ed.) (Hoboken: John Wiley \& Sons, Inc.) p. 225

10. Doyle M P, Westrum L J, Wolthuis W N E, See M M, Boone W P, Bagheri V and Pearson M M 1993 J. Am. Chem. Soc. 115958

11. Padwa A, Austin D J, Price A T, Semones M A, Doyle M P, Protopopova M N, Winchester W R and Tran A 1993 J. Am. Chem. Soc. 1158669

12. Doyle M P and Ren T 2001 Prog. Inorg. Chem. 49113

13. Doyle M P, Griffin J H, Bagheri V and Dorow R L 1984 Organometallics 353

14. Sheehan S M, Padwa A and Snyder J P 1998 Tetrahedron Lett. 39949

15. Padwa A, Snyder J P, Curtis E A, Sheehan S M, Worsencroft K J and Kappe C O 2000 J. Am. Chem. Soc. 1228155

16. Nakamura E, Yoshikai N and Yamanaka M 2002 J. Am. Chem. Soc. 1247181

17. Nowlan D T, Gregg T M, Davies H M L and Singleton D A 2003 J. Am. Chem. Soc. 12515902

18. Hansen J, Autschbach J and Davies H M L 2009 J. Org. Chem. 746555

19. Berry J F 2012 Dalton Trans. 41700

20. Davies H M L and Morton D 2011 Chem. Soc. Rev. 40 1857

21. Kornecki K P, Briones J F, Boyarskikh V, Fullilove F, Autschbach J, Schrote K E, Lancaster K M, Davies H M L and Berry J F 2013 Science 342351

22. Fiori K W and Du Bois J 2007 J. Am. Chem. Soc. 129 562

23. Fiori K W, Espino C G, Brodsky B H and Du Bois J 2009 Tetrahedron 653042

24. Perry R H, Cahill T J, III, Roizen J L, Du Bois J and Zare R N 2012 Proc. Nat. Acad. Sci. U.S.A. 10918295

25. Zalatan D N and Du Bois J 2009 J. Am. Chem. Soc. 131 7558

26. Kornecki K P and Berry J F 2011 Chem. Eur. J. 17 5827

27. Kornecki K P and Berry J F 2012 Eur. J. Inorg. Chem. 562

28. Doyle M P 2006 J. Org. Chem. 719253

29. Kornecki K P and Berry J F 2012 Chem. Commun. 48 12097

30. Pap J S, George S D and Berry J F 2008 Angew. Chem. Int. Ed. 4710102

31. Chen W Z, De Silva V, Lin C, Abellard J, Marcus D M and Ren T 2005 J. Clust. Sci. 16151

32. Long A K M, Yu R P, Timmer G H and Berry J F 2010 J. Am. Chem. Soc. 13212228

33. Long A K M, Timmer G H, Pap J S, Snyder J L, Yu R P and Berry J F 2011 J. Am. Chem. Soc. 13313138

34. Timmer G H and Berry J F 2012 Chem. Sci. 33038

35. Chakravarty A R, Cotton F A and Tocher D A 1985 Inorg. Chem. 241263

36. Corcos A R, Long A K M, Guzei I A and Berry J F 2013 Eur. J. Inorg. Chem. 20133808 